\title{
Marica Larocchi, Luogo e formula. Per una lettura d'"Illuminations" di Arthur Rimbaud
}

\section{Mario Richter}

\section{(2) OpenEdition}

1 Journals

\section{Edizione digitale}

URL: http://journals.openedition.org/studifrancesi/6052

DOI: $10.4000 /$ studifrancesi.6052

ISSN: 2421-5856

\section{Editore}

Rosenberg \& Sellier

\section{Edizione cartacea}

Data di pubblicazione: 1 mai 2011

Paginazione: 201

ISSN: 0039-2944

\section{Notizia bibliografica digitale}

Mario Richter, "Marica Larocchi, Luogo e formula. Per una lettura d"Illuminations" di Arthur Rimbaud», Studi Francesi [Online], 163 (LV | I) | 2011, online dal 30 novembre 2015, consultato il 10 janvier 2021 URL: http://journals.openedition.org/studifrancesi/6052 ; DOI: https://doi.org/10.4000/studifrancesi. 6052

Questo documento è stato generato automaticamente il 10 janvier 2021.

\section{(c) $(1) \ominus$}

Studi Francesi è distribuita con Licenza Creative Commons Attribuzione - Non commerciale - Non opere derivate 4.0 Internazionale. 


\title{
Marica Larocchi, Luogo e formula. Per una lettura d" Illuminations" di Arthur Rimbaud
}

\author{
Mario Richter
}

\section{NOTIZIA}

Marica Larocchi, Luogo e formula. Per una lettura d'“Illuminations" di Arthur Rimbaud, Lecce, Manni, 2009, pp. 268.

1 Questo libro riprende innanzitutto l'annoso problema riguardante la cronologia delle Illuminations. L'iniziale capitolo, intitolato Storia di un manoscritto, appunto una congettura che si conclude con una determinazione di date: «cosa mai facesse Rimbaud nel 1878 nel quartiere latino, ritrovo per eccellenza dei letterati parigini, è da porsi senza indugio in relazione col successivo possesso da parte di Sivry del manoscritto di Illuminations. È probabile che il musicista sia stato incaricato di persona di custodire l'opera in attesa di una sua futura pubblicazione. Né va escluso che Germain Nouveau abbia partecipato all'incontro; anzi, è possibile che questo sia avvenuto grazie alla sua mediazione, in quanto ottimo amico di Sivry. Le quinte che sigillano l'epoca di composizione d'Illuminations, si fissano così sugli anni 1873-1878» (p. 18). Risulta in tal modo ribadita la tesi, oggi pressoché da tutti ammessa, secondo cui la composizione delle Illuminations è complessivamente successiva a Une saison en enfer.

2 La parte più consistente del saggio è poi occupata dalla riproduzione dei testi originali, dalla loro traduzione a fronte (di convincente qualità) seguita da una loro articolata 'lettura' critica, dalla quale il lettore può spesso trarre interessanti indicazioni (a proposito di Dévotion, occorre tuttavia precisare che il testo della «Vogue», l'unico che si conosca, separa il sesto dal settimo capoverso con una virgola e non con un punto, dettaglio grafico non secondario per una 'lettura' corretta del testo). 
3 I rilievi presenti nel capitolo Temi e procedure d'“Illuminations" offrono un apporto critico di indubbia utilità per chiunque voglia accostarsi alla particolare lingua creata da Rimbaud per questa fondamentale parte della sua opera, sulla cui strutturazione, diversamente da Todorov e Guyaux, così giudica M. Larocchi: «...noi riteniamo che Illuminations costituisca una raccolta sistematica di poemi in prosa, redatti nel segno di una logica perturbata e paradossale che, tuttavia, non è mai di ostacolo al flusso narrativo. Infatti, una sorta di aneddoto di fondo si mantiene latente ma percepibile persino nelle pièces più enigmatiche» (p. 234).

4 Il libro si conclude con due appendici (La critica e il problema della datazione di Illuminations e Biografia dettagliata dell'Autore relativa al periodo compreso fra il 1873 e il 1878, anni di composizione di Illuminations) e con una bibliografia. 